\title{
DA MECÂNICA DAS PAIXÕES À GEOMETRIA DOS AFETOS: UMA REVISÃO DAS TEORIAS DAS EMOÇÕES FORMULADAS NA MODERNIDADE
}

\author{
FROM THE MECHANICS OF PASSIONS TO THE GEOMETRY OF AFFECTS: A REVIEW OF THE \\ THEORY OF EMOTIONS FORMULATED IN THE MODERN ERA
}

Diego Candido Abreu

1 Doutor em Estudos daLinguagem pela PUC-Rio. Professor EBTT do IFMA Campus-Codó. diegocurciodeabreu@gmail.com
ABREU, D. C. Da mecânica das paixões à geometria dos afetos: uma revisão das teorias das emoções formuladas na modernidade. Akrópolis, Umuarama, v. 29, n. 2, p. 175-183, jul./ dez. 2021.

\section{DOI: 10.25110/akropolis.v29i2.8482}

REsUmo: O objetivo central deste trabalho é expor uma breve revisão das teorias das emoções desenvolvidas ao longo da Modernidade. Diante de um período histórico de tamanha abrangência, o presente artigo terá como enfoque as teorizações propostas por quatro pensadores: 1) Descartes, 2) Hume, 3) Leibniz; e 4) Espinoza. Além da apresentação dos esquemas conceituais que entabulam o fenômeno das emoções, este escrito também propõe uma discussão acerca dos pontos de aproximação e afastamento entre as teorias iluminadas, explicitando as possíveis interfaces entre as ideias dos pensadores abordados e os desdobramentos dessas teorias.

Palavras-chave: Teoria das Emoções; Descartes; Hume; Leibniz; Espinoza.

ABSTRACT: The main purpose of this work is to present a brief review of the theories of emotions coined throughout the Modern Era. Due to its historical length, this article focuses on the theoretical models proposed by four different thinkers: 1) Descartes; 2) Hume; 3) Leibniz; and 4) Spinoza. In addition to the presentation of the conceptual schemes that are at the base of the emotion phenomenon, this paper also proposes a discussion regarding the points of proximity and distance among the presented theoretical lines, explicating the possible interfaces among the ideas of the addressed authors and the consequences of those theories.

KEYwords: Theory of Emotions; Descartes; Hume; Leibniz; Spinoza. 


\section{INTRODUÇÃO}

Poucos temas têm instigado tanto a curiosidade humana ao longo da história das ideias como as nossas emoções ${ }^{3}$. Desde a antiguidade grega (MARCONDES, 2007), pensadores das mais distintas inclinações e áreas de formação debruçamse sobre o problema, escrutinando-o a partir de ângulos também plurais. A proficuidade de revisões históricas acerca de diferentes teorizações sobre as emoções evidencia a ubiquidade do interesse em tal esfinge, deixando claro não se tratar apenas de uma investigação do tempo presente.

$\mathrm{Na}$ contemporaneidade, a fascinação perante os afetos se inter-relaciona com um movimento de negação da tradição moderna, batizado com o sugestivo nome de PósModernidade (HARVEY, 1990). Tal corrente de pensamento, ancorada em uma interpretação crítica do legado da Civilização das Luzes, perscruta todos os pilares da Modernidade com olhos de enfrentamento, propondo formas alternativas de compreender o mundo, entabulado de maneira racionalizante, eidética e técnica pelo objetivismo moderno (ADORNO, 2009). Em meio a esse momento de insurgência, o interesse pela esfinge das emoções emerge como um novo flanco em que a batalha de superação do cânone da Modernidade é travada. Sendo a afetividade caracterizada como produto dos nossos instintos animalescos e de nossas forças intestinas durante o período de hegemonia do platonismo cientificista moderno, a Pós-Modernidade tem buscado promover a reconciliação com o universo das nossas paixões. Nesse paradigma, revalorizar o pathos implica não apenas impor uma nova forma de compreender o fenômeno das emoções, mas também assentar as bases de uma nova epistemologia, liberta dos grilhões de apagamento da subjetividade inerentes ao método moderno.

Ancorado na discussão trazida nos parágrafos anteriores, o presente artigo dispõe de um objetivo precípuo: apresentar uma concisa revisão das teorias das emoções formuladas durante a Modernidade. Sendo a contemporaneidade pós-moderna militantemente infensa tanto à estigmatização das paixões quanto ao dualismo frio do pensar das Luzes, torna-se imperativo que detenhamos um conhecimento aprofundado das

\footnotetext{
${ }^{3}$ Emprego os termos emoção, paixão, sentimento, afeto, afetividade e sentir de forma intercambiável. Para uma explicação minuciosa de tal postura teórica, ver Abreu (2018)
}

teorias das emoções propugnadas pelas diferentes linhas constitutivas dessa matriz de pensamento, de modo a tornar a crítica a ela endereçada mais teoricamente sólida e politicamente contundente.

Além desta introdução, o artigo conta com mais dois momentos. A seguir, exponho de forma sintética os modelos de inteligibilidade acerca das emoções construídos, respectivamente, por Descartes, Hume, Leibnize Espinoza. Na sequência, componho um quadro teórico em que os pontos de interseção, ruptura e complementariedade entre as visões exibidas são destacados. Ao cabo, trago algumas breves considerações acerca da pesquisa empreendida.

\section{A ASCENSÃO DA MODERNIDADE E A REFLEXÃO SOBRE AS EMOÇÕES}

A Modernidade está relacionada com a ideia de novidade desde sua etimologia, remetendo ao latim modo, advérbio que pode ser traduzido como "neste instante" ou "agora mesmo" (MARCONDES, 2007). Além da noção de novo, a Modernidade carrega em seu seio duas concepções centrais, relacionadas intimamente com a teoria de seus pensadores mais proeminentes: o progresso e a individualidade. Acerca desta, podemos pontuar que no pensamento que dominou a Europa a partir do século $\mathrm{XVI}$, o foco de interesse investigativo desloca-se de uma suposta harmonia do universo ou de uma busca pela aproximação perante a perfeição divina para o sujeito, adornado por todas suas complexidades e idiossincrasias. No que tange ao progresso, observamos que o ideário moderno inverte uma perspectiva dominante acerca da dinâmica ético-epistemológica da história, cujo movimento tendia a valorar superior aquilo que remetia ao antigo, clássico ou tradicional. No bojo desse novo pensamento, a história é vista como uma flecha que aponta para frente, furtando-se de venerar os marcos do passado em nome dos avanços e conquistas a serem desbravados no futuro (MARCONDES, 2007).

Conforme aponta Marcondes (2007, p. 143), quatro fatores históricos contribuíram de forma relevante para o desenvolvimento da filosofia moderna: "o humanismo renascentista do século $\mathrm{XV}$, a descoberta do novo mundo, a Reforma protestante do século $\mathrm{XVI}$ e a revolução científica do século XVII"; teçamos algumas linhas sobre o primeiro fator. A contribuição central do humanismo reside em seu redirecionamento do olhar filosófico 
para o indivíduo, como a instância mais legítima sobre a qual a ciência e a filosofia deveriam se debruçar. O pensamento de autores como Maquiavel e Montaigne evidencia o distanciamento sistemático de uma concepção de sociedade idealizada a partir de um referencial harmonioso e ordenado, em reconciliação com um mundo caótico e instável. Nesse sentido, a célebre frase de Protágoras (MARCONDES, 2007) "o homem é a medida de todas as coisas", consagrada como mote do humanismo, representa uma ruptura diante da filosofia medieval, que tergiversava o indivíduo enquanto mantinha os olhos fitos no céu.

Edificando como marco fundacional desse período histórico os primórdios do movimento humanista e encontrando sua crise e declínio com a produção e os desdobramentos da obra de Kant, podemos perceber que uma apresentação, ainda que panorâmica, dos estudos sobre as emoções desenvolvidos ao longo desse período demanda alguma forma de divisão mais refinada. Dessa forma, considerando a efervescência teórica do período e a quantidade oceânica de produção intelectual, destacarei a teoria de apenas alguns autores, tendo como critério fundamental de escolha a relevância e a singularidade de seus pensamentos. Em ordem de apresentação, os pensadores abordados são: Descartes, Hume, Leibniz e Espinoza. Comecemos pelo filósofo francês.

\subsection{A dúvida como método: Descartes e a Mecânica das paixões}

Tido como o pioneiro da filosofia moderna em sua forma mais conclusa ao lado dos empiristas ingleses, Descartes nasceu em 1596 na França, no berço de uma família pequeno-nobre (MARCONDES, 2007). O pensamento cartesiano se constitui em clara oposição à reflexão medieval, apologizando um novo modelo de investigação, balizado pelas ideias da nova ciência. Uma das preocupações centrais da obra cartesiana encontra-se na comprovação da possibilidade do conhecimento e na consequente superação da teoria cética. No bojo dessa preocupação, surge a sua colocação mais célebre: "penso, logo existo" (DESCARTES, 2000). Essa pequena frase representa o ponto final de um argumento erigido por Descartes, no qual o autor, partindo dos princípios do próprio ceticismo, buscou consolidar a hipótese da dúvida metódica. Para o filósofo, ao expormos todas nossas ideias e teorias ao crivo da dúvida, a única certeza que podemos sustentar de forma evidente é nossa capacidade de duvidar, ou seja, a própria existência do ser pensante se comprova pela sua capacidade de duvidar de tudo, inclusive de si.

Próximo ao fim de sua produção intelectual, Descartes redigiu algumas considerações acerca das emoções, em um texto que o filósofo denominou As paixões da alma (DESCARTES, 1973). Esse escrito se encontra em meio às correspondências de Descartes com a Princesa Elisabete da Boêmia. Esta, em uma de suas epístolas, questiona o pensador acerca da evidente supremacia das emoções, em sua natureza fisiológica, diante da espiritualidade da alma (GOREVAN, 2015). Em resposta, Descartes apresenta uma teoria estritamente corpórea das paixões, alegando investigá-las pela perspectiva de um fisiologista, não de um filósofo moral (GOREVAN, 2015). Para o aristocrata francês, os organismos são máquinas orgânicas, tendo o seu funcionamento regido pelas leis da mecânica que balizam as inter-relações entre suas distintas partes. Dessa forma, o corpo possui autonomia de movimento em relação às deliberações da alma, sendo às ações exclusivamente corpóreas atribuído o estatuto de paixões, pois sua existência não provém de uma volição da alma.

Descartes define as paixões como "percepções, sensações ou excitações da alma que são referidas em particular e que são causadas, mantidas ou reforçadas pelo movimento dos espíritos animais" (GOREVAN, 2015, p. 3). O autor preconiza a existência de seis paixões primordiais, a partir das quais as demais emoções se fundam: amor, desejo, alegria, tristeza, admiração e ódio. A partir dessa constituição teórica inicial, Descartes busca evidenciar a estrutura orgânico-fisiológica que impinge o movimento e a organização dessas emoções fundadoras. Ontologicamente, os afetos estão subordinados aos movimentos dessas micropartículas, sendo as representações mentais das paixões um produto resultante da percepção desse movimento pelo corpo. Assim, a circulação dessas partículas extremamente pequenas, que percorrem nosso corpo pelo sangue devido ao calor exalado pelo movimento do coração, configura as respostas ideacionais que constituem a esfera psicológica das emoções. As perturbações ocasionadas pelo afluxo desses corpos ínfimos próximos à glândula pineal - local de residência material da alma em nosso corpo - definem o caráter singular das emoções humanas. Graças a essa proximidade, por um lado, as paixões se 
diferenciam de outras sensações mais automáticas e imediatas como a fome e a sede. Por outro lado, as emoções, ainda que não completamente, estão sujeitas aos juízos da alma, que, mediante a força do hábito, pode exercer alguma forma de tutela e senhoria sobre as paixões (GOREVAN, 2015). Porém, pontua Descartes, as emoções, mesmo quando subsidiadas por algum trabalho volitivo, remanescem com suas raízes no movimento fisiológico dos espíritos animais, distinguindo-se, portanto, de uma atitude intelectual sustentada exclusivamente pela alma.

Mesmo tratadas como inferiores em relação aos juízos da razão, as emoções, basicamente, possuem um caráter virtuoso para o pensamento cartesiano. Assim, as paixões balizam e moderam a intensidade da relação entre nós e o mundo que nos cerca, direcionando a atenção da mente para as necessidades que se apresentam mais frementes no que tange à busca natural de preservação da nossa vida. Portanto, as emoções na reflexão cartesiana desempenham o papel da animalidade em nossa existência que, quando virtuosamente manejada pela alma, pode configurar-se como um dispositivo instintivo de conservação importante, porém, cuja tempestividade deve ser domada.

Apesar das relevantes contribuições da obra cartesiana no estudo das emoções - tendo influenciado algumas correntes teóricas cuja presença se estende até os nossos dias - suas postulações vêm sendo sistematicamente criticadas por autores avessos a um entendimento visceral das emoções. Uma das críticas mais proeminentes foi apresentada por Vygotsky (2004). Segundo o psicólogo soviético, a visão de Descartes pode ser entendida como mecanicista, a-histórica e espiritualista (MACHADO, FACCI \& BARROCO, 2011). Inicialmente, a teoria cartesiana configurase como mecanicista devido ao entendimento das emoções como um produto da relação automática e determinista entre o corpo, a alma e o meio. Da mesma forma, esse pensamento é a-histórico graças ao seu olvido acerca dos aspectos inerentes ao desenvolvimento desse fenômeno no indivíduo, contemplando tanto a esfera biológica (filogenética e ontogenética) quanto, e especialmente, os aspectos socioculturais. Logo, para o pensamento cartesiano, a configuração ontológica das emoções seria idêntica para um bebê persa no século XIX, uma mulher romana no século III e para um idoso brasileiro no século XXI. Por fim, o caráter espiritualista da teoria de Descartes reside na forma como o autor articula o encontro orgânico- metafísico entre o corpo e a alma. Ao reunir em um ponto específico do cérebro (a glândula pineal) a materialidade corpórea e a imaterialidade da alma, Descartes propõe um salto ontológico insustentável a partir de uma visão materialista. Assim, a concepção teológica da filosofia cartesiana contamina sua teoria das paixões, transformando-a em uma quimera constituída a partir da junção de dois planos distintos: a materialidade fisiológica e a espiritualidade da alma.

Como já destacado, ao lado do pensamento racionalista na inauguração do ideário moderno figura o empirismo britânico. Dada a importância dessa corrente teórica para a constituição do período em tela, torna-se relevante a apresentação do seu olhar acerca do fenômeno das emoções, enfatizando a teorização de um de seus autores mais eminentes: David Hume.

\subsection{O estruturalismo hedônico: David Hume e a teoria empirista das emoções}

O ponto de partida da filosofia do escocês David Hume e dos demais empiristas é a constatação de que nosso saber sobre a realidade edifica-se a partir da experiência sensível empírica (MARCONDES, 2007). Nesse sentido, a epistemologia humiana privilegia o papel da percepção, preconizando que o critério valorativo de um determinado conhecimento assenta-se na sua proximidade da experiência sensitiva que o originou empiricamente. Essa centralidade atribuída à percepção impregna o entendimento de Hume acerca das emoções. Para o autor, os afetos representam formas de impressão (COLLIER, 2011) do indivíduo no mundo, sendo tal perspectiva denominada por alguns autores de teoria sentimentalista ${ }^{4}$. Porém, conforme argumenta Collier (2011), o sentimentalismo de Hume se distancia de uma posição ortodoxa sistematicamente criticada por, dentre outras razões, igualar as paixões a sensações fisiológicas como o formigamento de um membro ou as cócegas. O filósofo escocês propõe uma teoria de caráter híbrido, reconhecendo o papel dos elementos cognitivos e avaliativos na constituição das emoções, além da ligação desses elementos com a subjetividade do indivíduo em contato com um mundo material.

Apesar do reconhecimento da intervenção de elementos cognitivos em meio à trama das emoções, Hume critica a concepção

${ }^{4}$ Feeling theory. 
exacerbadamente intelectualizada dos afetos na tradição filosófica. Ancorado nessa crítica, o autor erige uma teoria afetiva articulada a um modelo de processamento de impressões e percepções do sujeito no mundo. No seio desse esquema, cada experiência de um indivíduo se constitui a partir de dois movimentos, sendo o primeiro deles afetivo e o seguinte, cognitivo (NORTON \& NORTON, 2000). Assim, por exemplo, ao experienciar um encontro com algo belo, o indivíduo, primeiramente, apreenderia esse momento de maneira afetiva: a beleza do objeto ou sujeito observado lhe causa uma sensação e um sentimento de prazer. Em seguida, o indivíduo responderia a esse encontro de forma cognitiva, admirando esteticamente a beleza vislumbrada ou sentindo-se orgulhoso, caso esse mesmo indivíduo possua alguma ligação de posse ou autoria com esse objeto belo.

No que tange ao desenvolvimento de cada emoção especificamente, Hume volta sua mirada para os elementos eliciadores e catalisadores da paixão no indivíduo. Após uma investigação laboriosa, o autor pontua as duas variáveis causais fundamentais na constituição da experiência emotiva: valência e agência. Aquela se refere à percepção individual da natureza prazerosa ou desprazerosa de uma certa qualidade, ou seja, se algo é percebido e, consequentemente valorado por nós, como sensorialmente bom ou ruim. Por sua vez, a agência está relacionada com a percepção individual de autoria/posse no que tange a uma dada qualidade, isto é, se um indivíduo atribui uma qualidade a si próprio ou a outrem. Com base nessa reflexão, Hume pontua que as emoções são inerentemente balizadas por essa inter-relação entre agência e valência, constituindo-se sobre esse alicerce. O mapeamento bem-sucedido da infraestrutura agentivo-valorativa das nossas percepções (e julgamentos, consequentemente) acerca de uma certa situação nos permite um grau confiável de previsibilidade a respeito da experiência emotiva a ser vivida. Colocado de outro modo, as emoções, na concepção do empirismo de Hume, podem ser consistentemente reduzidas causalmente a um produto psicológico da dinâmica perceptiva (infra-)estruturante que impinge nossa experiência com o mundo.

\subsection{O caminho para a Perfeição: o pensamento de Leibniz sobre as emoções}

Inegavelmente, a filosofia cartesiana marcou 0 direcionamento do pensamento racionalista que a sucedeu. Mesmo os críticos mais céticos em relação aos seus pressupostos fundamentais a tomaram como alicerce de suas reflexões, ainda que suas ideias buscassem seguir caminhos diferentes. No correr do séc. XVII, epicentro histórico da modernidade, ganha força um movimento filosófico-estético que marcará os rumos da tradição moderna, cujos efeitos são observáveis até a contemporaneidade: a ruptura entre os modernos e os clássicos. Enquanto, de um lado, os autores partidários da tradição clássica defendem o retorno aos padrões estéticomorais da antiguidade, os modernos proclamam o ideal do progresso, que, assim como no caso dos avanços patrocinados pela ciência, deveria balizar a produção filosófica e artística regente na Europa (MARCONDES, 2007).

Um dos autores mais importantes a construir sua obra em oposição ao cartesianismo foi Leibniz. O filósofo alemão, nascido em meados do século XVII, alicerça seu pensamento sobre um terreno lógico e metafísico, distanciando-se do ceticismo de Descartes ao propor que uma investigação filosófica não deve, necessariamente, dar seus primeiros passos com base no crivo da dúvida tirânica, mas sim lançando luz sobre as razões que levam a um determinado indivíduo discordar ou concordar com uma dada afirmação em um certo grau (MARCONDES, 2007). Nesse sentido, Leibniz preconiza uma visão holística acerca dos fenômenos observados e sobre os quais tecemos julgamentos sobre sua veracidade e qualidade. Porém, nenhum objeto ou discurso se sustenta como verdadeiro apenas com seus próprios pés, ou seja, isolado do restante do universo, com o qual compõe uma totalidade. Outro ponto fundamental do pensamento de Leibniz reside no papel atribuído ao intelecto humano na constituição do conhecimento, cujo protagonismo antagoniza com a visão do empirismo. No que se refere a esse aspecto, Leibniz afirma que o conhecimento antecede ontologicamente a experiência empírica, ou seja, se institui aprioristicamente no intelecto humano. De tal forma, a centralidade atribuída pelos empiristas à esfera fenomênica do conhecimento empobrece a investigação filosófica, pois a torna refém da contingência dos encontros do mundo em detrimento de uma busca por compreender as bases racionais imutáveis da realidade.

Ao contrário de outros autores modernos, Leibniz não erigiu uma teoria dedicada às emoções, porém muitas de suas contribuições aos estudos sobre o tema se encontram em inferências 
realizadas a partir de um olhar minucioso em direção à sua filosofia - prática sugerida por sua própria obra. A teoria psicológica de Leibniz se assenta em uma concepção paralelista a respeito da relação entre o corpo e a alma. Sendo assim, o autor compreende que ambos elementos constituintes da existência humana, apesar de agirem no mundo de forma sincronizada entre si, o fazem sem intervir mutuamente, ou seja, como se habitassem dimensões paralelas. A metáfora apresentada por Leibniz para clarear o seu modelo teórico paralelista aproxima o corpo e a mente a dois relógios, que trabalham simultaneamente a partir da automação divina (ROINILA, 2011).

Pautado no seu esboço paralelista, Leibniz entende as emoções como elementos relacionados à dimensão mental nos seres humanos. No entanto, assentado em sua perspectiva de totalidade, podemos perceberqueas manifestações emocionais na alma possuem um paralelo sincronizado no corpo. Nesse espectro binário, as paixões são balizadas pela dinâmica relacional do indivíduo com o mundo, isto é, pelo caráter ativo ou passivo do encontro do sujeito com o seu meio. Porém, como já pontuado, as interações na perspectiva leibniziana não se dão de forma atomizada, mas holística com toda a realidade. Desse modo, o autor relaciona a obtenção de uma forma mais perfeita do eu ao prazer enquanto, por sua vez, a imperfeição caminha de mãos dadas com a dor. Outrossim, a natureza ontológica da dor habita no bojo de um encontro do sujeito com o mundo no qual o polo passivo dessa relação representa uma paixão para o indivíduo e uma ação para o meio. Inversamente, um encontro em que o papel ativo é desempenhado pelo indivíduo se logrará prazeroso para este (ROINILA, 2011). Portanto, como evidenciado nessa reflexão, para o pensamento leibniziano, a regência das ações do indivíduo perante o mundo enseja paixões articuladas com o prazer sensorial (a alegria, a felicidade, etc.) enquanto, por outro lado, uma posição passiva do sujeito perante suas circunstâncias o torna prisioneiro de sensações dolorosas que, por sua vez, fomentam emoções negativas - como a tristeza e o medo.

Outro ponto central da teorização de Leibniz sobre as emoções pode ser observado na distinção entre as paixões estritamente corpóreas e as emoções intelectuais. Enquanto aquelas nos guiam à imperfeição e à preservação instintiva do ser, estas nos aproximam do que enriquece nossa existência e a torna mais perfeita. Acerca dessa questão, Roinila (2011, p. 933) pontua que "as paixões intelectuais nos motivam a agir racionalmente, abrindo espaço para o surgimento da ação da vontade." Outro aspecto distintivo entre as paixões carnais e intelectuais repousa em seu movimento em face do próprio indivíduo. As emoções corpóreas possuem uma dinâmica exógena, surgindo a partir da percepção de algum elemento externo, cuja impressão provoca um conjunto de reações fisiológicas e emotivas. 0 contrário pode ser notado nas paixões da alma: estas florescem no jardim da própria razão humana, mais especificamente, na nossa busca volitiva pela perfeição e pela similitude com o divino.

Um exemplo de emoção do espírito abordada por Leibniz é a alegria intelectual. Para o autor, esse afeto surge como um sentimento de perfeição, uma ação que nos aproxima gradativamente de Deus, a perfeição absoluta. Esse movimento mental de perfeição, paralelamente, afeta nosso corpo, energizando-o e tornando-o mais poderoso, ou, de forma mais alinhada à terminologia leibniziana, ensejando uma configuração física mais perfeita, que reflete a busca da alma por harmonizar-se metafisicamente à Divindade universal. Nesse aspecto está o fulcro da concepção de Leibniz acerca das emoções: elas orbitam em uma dinâmica de aproximação e afastamento da perfeição universal, cujo modo de percepção humana se dá através da harmonia e da beleza. Sendo assim, uma situação que me torne mais harmonizado com o universo me desperta afetos positivos; já uma contingência que corrompa a minha perfeição, fomenta o oposto - afetos negativos, que denunciam o meu afastamento da pureza celestial.

Além de Leibniz, outro pensador racionalista, cuja matriz teórica rompeu com as premissas fundacionais do cartesianismo, foi Espinoza. No entanto, diferente do filósofo alemão, Espinoza dedicou parte importante de sua produção à reflexão e ao entendimento do fenômeno dos afetos, sendo a sua contribuição de grande valor para a constituição de diversas correntes teóricas que encontram espaço até nossos dias. À sua teoria, a seção subsequente será dedicada.

\subsection{Deus Sive Natura: A geometria dos afetos de Espinoza}

Holandês de ascendência portuguesa, Espinoza nasceu e viveu ao longo do século XVII. Tendo mergulhado profundamente na educação de tradição judaica e teológica, o autor possuía conhecimento contundente de diferentes 
correntes filosóficas, dentre elas, o pensamento cartesiano. Apesar da influência de Descartes nos primórdios da edificação de sua filosofia, Espinoza gradativamente se afasta das premissas centrais da filosofia de seu mestre, mesmo ainda guardando com este alguns tangenciamentos, como o próprio método geométrico que baliza sua produção (MARCONDES, 2007). A grande obra espinozana é a sua Ética (1979), na qual o autor, de forma sistemática e organizada, apresenta os aspectos centrais da sua filosofia. Devido à sua concepção teológica, que igualava o real e à natureza imanente, Espinoza foi acusado de ateísmo, situação que gerou dificuldades financeiras e sociais para a continuação da vida do autor. Ainda nessa obra, Espinoza expõe a sua reflexão sobre as emoções, trazendo sua teoria geométrica dos afetos.

Espinoza buscou entender as emoções a partir de uma perspectiva geométrica, em que cada afeto possui um correspondente contrário que, eventualmente, o espelha ou o anula. Dessa forma, a alegria e a tristeza desempenham um papel fundamental na teoria afetiva de Espinoza, sendo sua ocorrência em um determinado encontro com o mundo responsável por elevar ou decrescer a nossa potência de agir. Ao lado destes, o desejo, definido pelo autor como "o esforço pelo qual cada um busca conservar seu próprio ser" (ESPINOZA, 1979), forma a trinca que constitui o terreno fundante de todas as emoções humanas.

Em seu materialismo estrito, Espinoza não preconiza uma separação ontológica entre o corpo e a alma, entendendo como análoga a descendência substancial de ambos - as quais representam apenas diferentes formas instanciativas do real. Assim, o pensador luso-holandês lança uma aura de descrença sobre a teoria do livre-arbítrio - que baliza o pensamento cartesiano - concebendo, portanto, as decisões tomadas como resultado material de uma complexa trama agonística de apetites. Destarte, nossa ação é balizada pelo afeto (ou grupo de afetos) que sagram-se temporariamente hegemônicos no seio dessa caótica convulsão afetiva que rege a vida no mundo. Os juízos e avaliações cognitivas, antes de definirem o curso de uma determinada ação, apenas oferecem explicações e sistematizações intelectivas para uma ação que se impõe à nossa consciência como um fato - um encontro idiossincrático de potências, apetites e afetos que se concatena em uma dada alteração no estatuto da relação do indivíduo com o mundo. Ancorada nessa reflexão, torna-se mais límpida a conhecida afirmação de Espinoza: "não é por julgarmos uma coisa boa que nos esforçamos por ela, (...) que a apetecemos, que a desejamos, mas, ao contrário, é por nos esforçarmos por ela, (...) por apetecê-la, por desejá-la, que a julgamos boa" (ESPINOZA, 1979).

Como já ressaltado, nesse complexo jogo de entrechoques afetivos, a alegria e a tristeza possuem protagonismo central. Assim como toda a teoria espinozana, essas emoções são definidas antagonicamente em um espectro geométrico. Para Espinoza, "a alegria é a passagem do homem de uma perfeição menor para uma perfeição maior" (ESPINOZA, 1979); enquanto, simetricamente oposta, "a tristeza é a passagem do homem de uma perfeição maior para uma perfeição menor" (ESPINOZA, 1979).

No que se refere à sua funcionalidade na dinâmica da vida humana, alegria / tristeza regulam nossa energia vital e oferecem o alicerce para o surgimento dos demais afetos, que ganham cores a partir de duas instâncias: a consciência acerca do ganho ou perda de potência de agir no corpo do indivíduo e o juízo avaliativo de caráter psíquico, que associa o nexo de causalidade de um dado afeto com a (in-)ação desse indivíduo no mundo. Sendo assim, na teoria geométrica, outras emoções surgiriam a partir da alegria e da tristeza: o amor se constitui a partir da alegria acompanhada da consciência de sua causa enquanto o ódio representa o seu perfeito inverso, tristeza consciente sobre sua causa; a esperança representa uma alegria presente em relação a uma projeção futura enquanto seu perfeito contrário, o temor, aviva uma tristeza projetada no horizonte. Nesse aspecto de sua teoria, Espinoza rompe, ao mesmo tempo, com o mecanicismo fisiológico e o idealismo de Descartes, entendendo os afetos como um fenômeno intrinsecamente psíquico e, ao mesmo tempo, radicalmente material, condicionado pelo nosso modo afetivo de conhecer e inferir causalidades no mundo (MAGIOLINO, 2010, p. 75).

Encerrada a apresentação da concepção espinozana de afeto, concluo esta seção dedicada a uma revisão das teorias das emoções mais proeminentes na aurora da Modernidade. No momento seguinte, trago uma breve discussão acerca dos pontos de contato e distanciamento entre as visões apresentadas. 


\section{ENTRE O DUALISMO CARTESIANO E O HOLISMO DE ESPINOZA: CONTATOS E ATRITOS ENTRE AS TEORIAS DAS EMOÇÕES DA MODERNIDADE}

Como explicitado por Marcondes (2007), duas correntes filosóficas dominaram a reflexão sobre o mundo no amanhecer do período moderno: o empirismo cientificista inglês e o racionalismo francês. Essas duas vertentes de pensamento, mutatis mutandis, mostram-se presentes na conformação do panorama teórico que rege o entendimento acerca do fenômeno das emoções na Modernidade. Apesar de uma série de diferenças, Descartes e Leibniz compartilham de alguns dos pressupostos fundamentais do racionalismo: a centralidade da razão e do eu humano na conformação dos objetos da realidade e a existência de um paralelismo entre corpo e alma. Esse esquema filosófico se contrapõe ao empirismo defendido por Hume. Para o pensador escocês, a experiência humana se converte no eixo fundamental a partir do qual todos os fenômenos reais devem ser pensados; apenas o conhecimento oriundo exclusivamente dela pode ser tido como confiável. Espinoza, adotando uma posição intermediária entre ambas as ilhargas, defende uma concepção eminentemente materialista dos afetos - preconizando-os como movimentos do corpo enquanto os integra em um sistema de constituição racionalista: um ordenamento geométrico.

Com base na demarcação filosófica estabelecida no parágrafo anterior, tornam-se patentes os pontos de tangência e distanciamento entre as teorias das emoções revisadas neste escrito. Primeiramente, cabe salientar que os modelos de inteligibilidade propostos por Descartes e Leibniz, apesar de assentados sobre um alicerce racionalista, possuem alguns pontos de distinção. O primeiro que merece nota é a inclinação fisiologista de Descartes, que se contrapõe de maneira frontal à natureza teológica e, em alguns aspectos, até mística de Leibniz. Outra divergência digna de menção é que o paralelismo inaugurado pelo pensamento leibniziano, apesar de fundar-se em uma separação explícita entre alma e corpo, unifica ambas as instâncias no marco da reflexão do filósofo sobre as mônadas. Em contrapartida, o cartesianismo tem como pedra angular justamente a dicotomização ontológica entre o âmbito da res cogitans (mundo das ideias) e res extensa (mundo da matéria e dos corpos).
Hume e Espinoza, apesar de rejeitarem o racionalismo cartesiano, bifurcam suas teorias das emoções em torno da caracterização desse fenômeno. Para o pensador luso-holandês, os afetos não são impressões ou sensações da mente, mas são forças que atuam sobre o corpo do sujeito, de modo a movê-lo em uma determinada direção. Por outro lado, Hume apresenta uma visão de caráter mais subjetivista, preconizando as emoções como percepções cognitivamente atentas de sensações e modificações no corpo. Portanto, há entre Espinoza e o filósofo escocês uma divergência acerca da constituição ontológica das emoções. Para o primeiro, os afetos são objetos em si, que arrebatam o indivíduo; para o segundo, as emoções são produto da interação cognitiva do sujeito com o seu meio e o seu corpo.

\section{CONSIDERAÇÕES FINAIS}

O pensamento da contemporaneidade se destaca por seu esforço de superação dos séculos de prostração diante do culto moderno à racionalidade e reconciliação com o aspecto afetivo da vida humana (MOITA LOPES, 2006). Como resultado, uma efervescência de pesquisas que apostam em abordagens heterodoxas na perscrutação do objeto das emoções tem marcado o cenário intelectual do ocidente nas últimas décadas, perfazendo um movimento denominado de Virada Afetiva (PAVLENKO, 2013). Na mesma medida que esses estudos escavam uma literatura esquecida ou estigmatizada no passado por sua visão condescendente em relação às paixões (obras de pensadores como Nietzsche ou Kierkegaard), ensaia-se um afastamento crítico de teorias modernas - muitas delas, defensoras de um logocentrismo militante. O efeito colateral dessa ojeriza teórica é a desnutrição intelectual em relação a séculos de reflexão sobre os afetos. Afinal, ainda que algumas das premissas que orientaram as empreitadas da Modernidade de pesquisar os afetos possam ser contestadas, a ideia de que a totalidade desse conhecimento deva ser sacrificado vai na contramão de um trabalho coletivo de produção de saber.

Orientado por essa compreensão, o presente artigo voltou seu olhar sobre algumas das teorias das emoções que constituíram o arcabouço de inteligibilidade moderno sobre o tema, visando a tornar mais acessível essa plêiade de discussões para pensadores contemporâneos que se 
interessem por essa esfinge. Inúmeras pontuações críticas podem ser feitas em relação a certas ideias defendidas pelos pensadores modernos: desde a extremada sacralização da racionalidade até uma redução dos afetos a impulsos ou forças animalescas. Porém, tal esforço desconstrutivo deve vir acompanhado de um conhecimento profundo acerca do ideário a ser impugnado; caso contrário, corre-se o risco de substituir o logocentrismo característico da Modernidade por um patocentrismo pós-moderno. Em ambos os casos, abandona-se o impulso científico de desbravar os mistérios da afetividade em troca de um culto pouco crítico de algumas de suas nuances.

\section{REFERÊNCIAS}

\section{ABREU, D. C. $O$ inglês à flor da pele:}

investigando o processo de construção discursiva das experiências emocionais em trajetórias de aprendizagem de língua inglesa (Dissertação de Mestrado). Pontifícia Universidade Católica do Rio de Janeiro, Departamento de Letras, 2018.

ADORNO, T. Dialética Negativa. Rio de Janeiro: Zahar, 2009.

COLLIER, M. Hume's Science of Emotions: Feeling Theory without Tears. Hume Studies. Volume 37(1), 2011. p. 3-18.

DESCARTES, R. As paixões da alma. São Paulo: Abril Cultural, 1973 (col. Os Pensadores).

. Meditações metafísicas. São Paulo:

Martins Fontes, 2000.

ESPINOZA, B. A Ética. Ed. Abril, São Paulo, 1979.

GOREVAN, P. Descartes and the Education of the Emotions. FORUM. Volume 1, 2015.p. 301-309.

HARVEY, D. The condition of postmodernity. Oxford/Cambridge, Basil Blackwell, 1990.

MACHADO, L. V.; FACCI, M. G. D.; BARROCO, S. M. S. Teoria das emoções em Vygotsky. Psicologia em Estudo. 16(4), 2011. p. 647-657.

MAGIOLINO, L. L. S. Emoções humanas e significação numa perspectiva históricocultural do desenvolvimento humano: Um estudo teórico da obra de Vigotski. Tese de
Doutorado, Faculdade de Educação, Universidade Estadual de Campinas, Campinas, SP, 2010.

MOITA LOPES, L. P. Uma linguística aplicada mestiça e ideológica: interrogando o campo como linguista aplicado. In: (Org.). Por uma linguística aplicada indisciplinar. São Paulo: Parábola, 2006, p. 13-43.

NORTON, D. F.; NORTON, M. J. A Treatise of Human Nature. New York: Oxford University Press, 2000.

PAVLENKO, A.The Affective Turn in SLA: From 'Affective Factors' to 'Language Desire' and 'Commodification of Affect'. In: The Affective Dimension in Second Language Acquisition. Ed: BIELSKA, J.; GABRYS-BARKER, D.; Salisbury. 2013. pp. 5-61.

ROINILA, M. Leibniz on Emotions and the Human Body. In: HERBERT, B.; JÜRGEN, H.; SVEN, E. (eds.). Natur und Subjekt (IX. Internationaler Leibniz-Kongress Vorträge). Leibniz Geschellschaft, 2011.

VYGOTSKY, L. S. Teoría de las emociones: estudio histórico-psicológico. Madrid: Akal, 2004.

\section{DE LA MECÁNICA DE LAS PASIONES A LA GEOMETRÍA DE LOS AFECTOS: UNA REVISIÓN DE LAS TEORÍAS DE LAS EMOCIONES FORMULADAS EN LA MODERNIDAD}

Resumen: El objetivo principal de este trabajo es presentar una breve revisión de las teorías de las emociones desarrolladas a lo largo de la Modernidad. Ante un período histórico tan amplio, este artículo se centrará en las teorías propuestas por cuatro pensadores: 1) Descartes, 2) Hume, 3) Leibniz; y 4) Spinoza. Además de presentar los esquemas conceptuales que establecen el fenómeno de las emociones. Esta investigación también propone una discusión sobre los puntos de aproximación y distancia entre las teorías iluminadas, explicitando las posibles interfaces entre las ideas de los pensadores abordados y los desarrollos de esas teorías.

Palabras clave: Teoría de las Emociones; Descartes; Hume; Leibniz; Spinoza. 